\title{
Value as the key concept in the health care system: how it has influenced medical practice and clinical decision-making processes
}

This article was published in the following Dove Press journal:

Journal of Multidisciplinary Healthcare

21 March 2017

Number of times this article has been viewed

\author{
Chiara Marzorati ${ }^{1,2}$ \\ Gabriella Pravettoni ${ }^{2,3}$ \\ 'Foundations of the Life Sciences, \\ Bioethics and Cognitive Science, \\ European School of Molecular \\ Medicine (SEMM), ${ }^{2}$ Applied \\ Research Division for Cognitive and \\ Psychological Science, European \\ Institute of Oncology, ${ }^{3}$ Department \\ of Oncology and Hemato-Oncology, \\ University of Milan, Milan, Italy
}

\begin{abstract}
In the last 10 years, value has played a key role in the health care system. In this concept, innovations in medical practice and the increasing importance of patient centeredness have contributed to draw the attention of the medical community. Nonetheless, a large consensus on the meaning of "value" is still lacking: patients, physicians, policy makers, and other health care professionals have different ideas on which component of value may play a prominent role. Yet, shared clinical decision-making and patient empowerment have been recognized as fundamental features of the concept of value. Different paradigms of health care system embrace different meanings of value, and the absence of common and widely accepted definition does not help to identify a unique model of care in health care system. Our aim is to provide an overview of those paradigms that have considered value as a key theoretical concept and to investigate how the presence of value can influence the medical practice. This article may contribute to draw attention toward patients and propose a possible link between health care system based on "value" and new paradigms such as patient-centered system (PCS), patient empowerment, and P5 medicine, in order to create a predictive, personalized, preventive, participatory, and psycho-cognitive model to treat patients. Indeed, patient empowerment, value-based system, and P5 medicine seem to shed light on different aspects of a PCS, and this allows a better understanding of people under care.
\end{abstract}

Keywords: health care system, value, value-based medicine, patient empowerment, clinical decision-making, patient centeredness

\section{Introduction}

Nowadays, the concept of value is a prominent topical issue in health care. Individual needs, wishes, preferences, and ethics influence the meaning of value which, in turn, is influenced by different cultures or historical periods. ${ }^{1}$ The necessity of finding better ways of redirecting the incentives away from volume and toward value pushes patients, physicians, policy makers, and other stakeholders to turn their attention toward what value means and what are the main features of this concept. ${ }^{2}$ Even if there is still no unanimous agreement on value's definition, it is commonly accepted that values in health care may be defined as normative guidelines helping us to evaluate actions or situations and influencing the decision-making process. ${ }^{3-5}$

Different studies point out how the definition of value changes according to the reference sample: doctors' values, most of the time, do not match the values of the patients, and vice versa. ${ }^{3,6,7}$

The presence of different opinions encourages some reputable organizations and associations to base their definitions of value on expert judgment or on empirical studies
Foundations of Life Sciences, Bioethics and Cognitive Sciences, European School of Molecular Medicine, Via Adamello 16, 20139 Milan, Italy

Email chiara.marzorati@ieo.eu 
that correlate attributes of value with a measurable outcome. According to this, the American Heart Association (AHA) underlines that, even though clinical efficacy and outcomes constitute the primary basis of good medical practice, value plays - together with costs - an important role, and it includes positive results in patient's outcome, safety, and satisfaction at a total cost that is reasonable and affordable. ${ }^{6}$ However, in 2008, the Institute of Medicine ${ }^{7}$ (IOM) held a 2-day workshop to explore key stakeholders' perspectives on value in health care, seeking to understand the meaning of value. Finding a mutually acceptable agreement among the different points of view, as expressed by patients, providers, economists, payers, and employers, is understandably complex. In fact, providers considered value on the basis of appropriateness of care and effective, evidence-based interventions; economic representatives defined value as the clinical benefit achieved for the money spent. Patients, however, place their attention on the ability of health care to satisfy their goals: a valuable intervention is a way of treating that also fulfills their needs. ${ }^{8}$ Indeed, from a patient's perspective, the burden of illness is not limited to disease status, but it is also important to consider quality of life (QoL) factors and, more precisely, health-related QoL, referring to its clinical dimension. Patient's needs are frequently measured taking into account different aspects of QoL, such as pain, emotional and cognitive functioning, or functional impairment. ${ }^{9,10}$ Moreover, a recent review ${ }^{11}$ on patient's perceptions of quality of care emphasizes how communication, health care access, and shared decision-making (SDM) are the key elements in a valuable health care environment.

Nowadays, even if we narrow our attention to the medical context, we are not able to identify the core features of a health care system based on value because every paradigm adopts different definitions of value. The absence of common and widely accepted meaning allows each movement in health care practice to take into account different components of value identifying different model, of care. The aim of this article is to provide an overview of the main approaches of the last 10 years that have considered value as the key theoretical concept. As we shall see, each movement adopts a particular definition of value leading to a different application of these paradigms in the health care system.

\section{From evidence-based medicine (EBM) toward value-based medicine (VBM)}

Two decades ago, the EBM was the first movement in health care that disregarded the paternalistic approach and revolutionized the idea of doing science. The EBM introduced a new way to make good clinical decisions: health care decisions should be based on the best available evidence mixed with the clinical expertise. ${ }^{12}$ External evidence and clinical expertise must be integrated with patients' preferences in making medical decisions about their care; only in this way, doctors will be able to identify the best interventions to maximize QoL of patients and minimize the cost of their care. ${ }^{13}$

Despite its success throughout the scientific world, some researchers have started asking whether this paradigm has been facing a crisis. Among different reasons, Greenhalgh et $\mathrm{al}^{14}$ suggested that, during the course of the years, EBM has forgotten the importance of individualism. Evidence should be understandable by all patients, practitioners, and other stakeholders, and they should share discoveries and fears to take reasonable decisions. ${ }^{14}$ At the same time, preferences, wishes, thoughts, and all individual aspects of patients were included in the conceptual label of value, becoming like a constellation of principles with an important role in life. Following the definition of Sackett et al ${ }^{15}$ with "patient values we mean the unique preferences, concerns and expectations each patient brings to a clinical encounter and which must be integrated into clinical decisions if they are to serve the patient."

In the last 10 years, to re-emphasize the importance of patients' preferences and QoL, new paradigms were born, turning their attention toward individual aspects and focusing on patient's value. Consequently, health care paradigms faced a shift from EBM to VBM. The term "value-based" was first introduced by Brown et al who defines this new paradigm as "the practice of medicine incorporating the highest level of evidence-based data with the patient perceived value conferred by health care interventions for the resources expended." ${ }^{\prime 16}$

EBM focuses its attention on clinical trial results and uses these data to provide the best care and, in the meanwhile, it usually ignores the importance of QoL improvement. Instead, the VBM leads to a higher level the discoveries of EBM calculating the value of operations in medical practice, based on pharmacoeconomic principles. ${ }^{1}$ The value is measured objectively by calculating the improvement in QoL and life expectancy after surgery: the result is the benefit derived from an intervention for the costs expended. ${ }^{17,18}$ In other words, VBM takes EBM to a higher level, including the QoL in the data analysis and interpreted the data in relation to the value and costs of an intervention. In so doing, VBM utilizes a health care economic cost-utility analysis where results could be interpreted in terms of \$/QALY (quality-adjusted life year), considering the dollars spent for the improvement in length of life and/or QoL on a continuum from 0.0 (death) to 1.0 (perfect health). ${ }^{19} \mathrm{QALY}$ is the arithmetic product of life 
expectancy combined with the measurement of the quality of remaining life years. ${ }^{20}$ The choice of the "right methodology" had been controversial, and they finally opted for a time trade-off cost-utility analysis since it would be applicable in any specialty of medicine, allowing a comparison across different interventions. ${ }^{18,21}$ Time trade-off methodology consists in "asking a person how many additional years he or she expects to live and, at the same time, how much time he or she would be willing to trade in return for a treatment that would guarantee their conversion in a normal health state." 21,22

In summary, VBM underlies the value aspect missing in EBM. In particular, EBM provides data that are converted to a measure of value through a cost-utility analysis and later combined with costs. ${ }^{1}$

Both VBM and EBM are paradigms involved in the growing complexity of decision-making process in health care because values and evidences affect all medical decisions. ${ }^{23,24}$ In fact, the increasing complication of evidences (from which clinical decision-making depends) and values (on which clinical decision-making is based) add up to a general growth of complexity in medicine, inspiring the necessity for an evidence and value-based practice (VBP).

Today, a variety of disciplines play a significant role in clinical decision-making in day-to-day practice: medical humanities, social sciences, decision analysis, and health economics are only some of those that influence patient's choices. ${ }^{25-28}$ Consequently, the aim of VBP is to integrate complex and conflicting values in the process of medical decision-making through a skill-based approach where clinicians could make medical decisions on the basis of scientific evidence and social, ethical, and political values. ${ }^{2,29}$

\section{A health care system based on value}

Another way to facilitate clinical decision-making and patient centeredness in health care is to organize the process of care around the concept of value: a health care system based on value has as a key component, the enhancement of patient-doctor communication, and the use of SDM. In accordance with this, a study showed that $69 \%$ of patients with lung cancer and $81 \%$ of patients with colorectal cancer experienced some difficulties in understanding the goals of their treatments and, consequently, they were not able to make aware decisions. ${ }^{30}$

Between 2006 and 2013 at the Institute for Strategy and Competitiveness, based at the Harvard Business School, Porter and Teisberg developed and proposed a new health care system based on value, "a breakthrough framework for redefining health care competition based on patient value." 31
According to value-based principles, a health care system should co-create and measure outcomes that are meaningful for patients with similar needs along the whole care pathway. ${ }^{32}$

A value-based health system should refer to three important principles. ${ }^{33}$ First, its proper goal should be the value it provides to the patient. In health care, the meaning of value varies along a continuum where psychological and physical outcomes meet costs. In fact, we can refer to value either from a psychological or from an economic perspective. Following Porter's idea, value is expressed as the best "health outcomes achieved per dollar spent." ${ }^{34}$ By "health outcomes", it is meant the health results that matter for the patient's condition over the care cycle, and by "costs", they refer to the total costs of care for patient's condition over the care cycle.

Second, treatment delivery should be based on medical conditions, and on the course of treatment, a patient has to undergo treatment and, finally, outcomes should be measurable and recorded. ${ }^{35}$ Data must be collected along the entire patient cycle of care because the outcomes achieved are more effective measures than the number of services delivered that we could not previously know if they are properly and successfully used. Moreover, outcomes should be interpreted on the basis of the true costs effectively delivered across the full care cycle because cost reduction without considering outcomes is dangerous and self-defeating. Value-based approaches consider cost measurement in a similar way to outcomes measurement, that is, around individual patients for all their care, rather than the cost of each organization delivering care. ${ }^{33,36}$

A particular example where cost measurement is always integrated with other patient's outcomes measurement is represented by the area of rare diseases. In such context, treatment options are not so widely available, and they are very expensive; the treatment care plan is usually highly personalized and centered on patient's health status and well-being taking into account the budget and patients' rated outcomes. ${ }^{37,38}$ The right strategy for a high-value health care delivery system also includes the organization of care around customer's preferences, implementing an integrated practice unit where multidisciplinary personnel works together to serve groups of patients with similar primary and preventive care needs. ${ }^{32,35}$

The attention toward the health care system shifts from a volume of activity approach to a value-based system, focused on results concretely obtained: ${ }^{34}$ as Porter and Lee affirm, this proposal is an "inevitable change": increasing value in health is the only one real solution. ${ }^{39}$ 


\section{Discussion}

A value-based system goes hand in hand with patient centeredness: today's fragmented health care system should move toward what patients want, considering and respecting their feelings in clinical procedures. Health care management is clearly moving toward a patient-centered system (PCS), where outcomes achieved and units organized around the patient's needs are the main guidelines for the delivery of high-value care. ${ }^{32,40}$ In fact, the IOM defines patient-centered care as "care that is respectful of and respective to individual patient preference, needs and values, and ensure that patient values guide all clinical decisions." ${ }^{41,42}$ Biological information must be integrated with beliefs and cognitive dispositions to empower patients and make them active participant in the treatment process. ${ }^{43}$

These features are also stressed by the P5 medicine approach to build a medicine that involves both medical and psycho-cognitive aspects. The health care system is moving toward a P5 medicine, which is a predictive, personalized, preventive, participatory, and psycho-cognitive medicine. The fifth $P$ refers to an integration among needs, values, cognitive dispositions, and medical information, between psychological and biological aspects. ${ }^{41}$ The necessity of a psychological and cognitive profile, instead of a mere diagnostic patient's classification, leads to an assessment with psychometric tools that include cognitive, decision-making, and mental aspects, as well as clinical ones.

The consideration of all these aspects is important to empower the patient, improve his/her QoL, and move toward their becoming an active decision-maker. ${ }^{43}$ To obtain a complete evaluation of medical treatment and to determine its value, it is necessary both balancing the costs with the benefits and considering the range of patient preferences or costs offsets: only with a careful assessment of all these aspects, high-value care will be provided. If we do not keep in mind outcomes, safety, and patient satisfaction, we could run into unexpected costs and lower level of care. Nowadays, different studies and updated clinical practice guidelines underline the importance of heeding both costs and values if we want a health care system effectively patient centered. New normative guidelines should include value and cost to achieve best performance measures and improve all health care system, as we can read on the report of American College of Cardiology/ AHA statement on cost/value methodology. ${ }^{6}$ These guidelines should give some important recommendations for appropriate exercise testing in patients with cardiovascular disease. ${ }^{44}$

On the basis of these recommendations, a recent randomized trial ${ }^{45}$ regarding diagnostic testing in women with suspected coronary artery disease demonstrated how the only difference between two groups (treadmill exercise electrocardiographic testing vs exercise myocardial perfusion imaging) was costs and not outcomes: the first intervention was more cost-effective and less invasive than the second one. This example shows how cost considerations can be informed by patient's values.

A good physician should be able to communicate in the right way with patients and to assess their health literacy and comprehension regarding different treatment options, possible benefits, and harm. ${ }^{46}$ These features are fundamental in the clinical decision-making process and are a cornerstone in a value-based health system. Indeed, one of the main recommendations to implement a value-based health system is to actively involve the patient in his or her process of care. ${ }^{33}$

At the same time, medicine and the whole health care system are facing a shift toward the patient empowerment paradigm that is linked with different aspects of patient participation. Although there is no unanimous agreement, current studies define this paradigm as a multidimensional concept where communication, decision, and health care system combined together and converge in the enhancement of the patient. ${ }^{47,48}$ Every definition emphasizes a specific aspect of the empowerment process: awareness, responsibility, participation in the care process, SDM, and patient-doctor communication. An empowered patient has developed specific abilities to interact with the health care system and to make better choices that include value for him or her. An empowerment process allows the patient to be an active and effective participant in their process of care and to look for valuable and useful information for their health. This is why empowerment should be considered in each step of the value chain and should influence the decision-making process in a PCS.

These features are also prominent in the value health care model and attach importance to psychological aspects influencing the process of care because empowered patients become effective people, able to choose valuable paths of care and of life.

\section{Conclusion}

The value-based system refers to a personalized care, where patient' expectations and needs are included in a holistic approach of medicine that considers physical, mental, and spiritual well-being. Physicians and patients should change their points of view, implementing a new process of care where they are actively and equally involved, each of them with their expertise: one with clinical knowledge and the other with his/her life. They are experts of different but equally important subjects. 
Patient empowerment, value-based system, and P5 medicine seem to shed light on different aspects of a PCS, and this allows a better understanding of patients and their families in managing health and health care.

Therefore, the value-based health system and patient empowerment should be considered together, two sides of the same coin. Patient's value may be fully expressed only when patients are the main actors of their care, and this means when they are fully empowered.

\section{Disclosure}

The authors report no conflicts of interest in this work.

\section{References}

1. Fulford KW. The value of evidence and evidence of values: bringing together values-based and evidence-based practice in policy and service development in mental health. J Eval Clin Pract. 2011;17(5):976-987.

2. Wieten S. 'What the patient wants': an investigation of the methods of ascertaining patient values in evidence-based medicine and values-based practice. J Eval Clin Pract. Epub 2015 Oct 30.

3. Altamirano-Bustamante MM, Altamirano-Bustamante NF, Lifshitz A, et al. Promoting networks between evidence-based medicine and values-based medicine in continuing medical education. BMC Med. 2013;11:39.

4. Gorini A, Pravettoni G. An overview on cognitive aspects implicated in medical decisions. Eur J Intern Med. 2011;22(6):547-553.

5. Riva S, Monti M, Iannello P, Pravettoni G, Schulz PJ, Antonietti A. A preliminary mixed-method investigation of trust and hidden signals in medical consultations. PLoS One. 2014;9(3):e90941.

6. Anderson JL, Heidenreich PA, Barnett PG, et al. ACC/AHA statement on cost/value methodology in clinical practice guidelines and performance measures: a report of the American College of Cardiology/American Heart Association Task Force on Performance Measures and Task Force on Practice Guidelines. J Am Coll Cardiol. 2014;63(21):2304-2322.

7. Institute of Medicine of the National Academies. Learning Healthcare System Concepts. The Roundtable on Evidence-Based Medicine, Institute of Medicine. Annual Report; 2008.

8. Young PL, Olsen L, McGinnis JM. Value in Health Care: Accounting for Cost, Quality, Safety, Outcomes, and Innovation: Workshop Summary. National Academies Press (US); 2010.

9. Muldoon MF, Barger SD, Flory JD, Manuck SB. What are quality of life measurements measuring? Br Med J. 1998;316(7130):542-545.

10. Fayers PM, Machin D. Quality of Life: The Assessment, Analysis and Interpretation of Patient-Reported Outcomes. Hoboken, NJ: John Wiley \& Sons; 2013.

11. Mohammed K, Nolan MB, Rajjo T, et al. Creating a patient-centered health care delivery system a systematic review of health care quality from the patient perspective. Am J Med Qual. 2016;31(1):12-21.

12. Sackett DL, Rosenberg WM. The need for evidence-based medicine. J R Soc Med. 1995;88(11):620-624.

13. Sackett DL, Rosenberg WM, Gray JM, Haynes RB, Richardson WS. Evidence based medicine: what it is and what it isn't. BMJ. 1996;312(7023) $71-72$.

14. Greenhalgh T, Howick J, Maskrey N; Evidence Based Medicine Renaissance Group. Evidence based medicine: a movement in crisis? BMJ. 2014;348:g3725.

15. Sackett DL, Straus SE, Scott Richardson W, Rosenberg W, Haynes RB. Evidence-Based Medicine: How to Practice and Teach EBM. 2nd ed. Edinburgh and London: Churchill Livingstone; 2000 - p. 1 emphasis in the original.
16. Brown MM, Brown GC, Sharma S. Evidence-Based Medicine to Value Based Medicine. Chicago, IL: AMA Press; 2005: 5-7, 125-149, 151-181, 193-217, 267-279, 319-324.

17. Brown GC, Brown MM, Sharma S. Value-based medicine: evidencebased medicine and beyond. Ocul Immunol Inflamm. 2003;11(3): $157-170$.

18. Busbee BG, Brown GC, Brown MM. Value-based medicine: a new paradigm to evaluate treatments for vitreoretinal diseases and other medical interventions. Int Ophthalmol Clin. 2004;44(4):155-172.

19. Brown GC. Value-based medicine: the new paradigm. Curr Opin Ophthalmol. 2005;16(3):139-140.

20. Brown MM, Brown GC, Sharma S, Landy J. Health care economic analyses and value-based medicine. Surv Opthalmol. 2003;48(2):204-223.

21. Brown MM, Brown GC, Sharma S. Value-based medicine and vitreoretinal diseases. Curr Opin Ophthalmol. 2004;15(3):167-172.

22. Brown MM, Brown GC. Value based medicine. Br J Ophthalmol. 2004;88(8):979-979.

23. Hunink MG, Glasziou PP. Decision Making in Health and Medicine: Integrating Evidence and Values. Cambridge: Cambridge University Press; 2001

24. Woodbridge K, Fulford KW. Whose Values. A Workbook for Values Based Practice in Mental Health Care. London: Sainsbury Centre for Mental Health; 2004.

25. Fulford KW. Values-based practice: a new partner to evidence-based practice and a first for psychiatry? Mens Sana Monogr. 2008;6(1): $10-21$.

26. Lucchiari C, Pravettoni G. Cognitive balanced model: a conceptual scheme of diagnostic decision making. J Eval Clin Pract. 2012;18(1): $82-88$

27. Riva S, Monti M, Iannello P, Antonietti A. The representation of risk in routine medical experience: what actions for contemporary health policy? PLoS One. 2012;7(11):e48297.

28. Renzi C, Riva S, Masiero M, Pravettoni G. The choice dilemma in chronic hematological conditions: why choosing is not only a medial issue? A psycho-cognitive perspective. Crit Rev Oncol Hematol. 2016;99:134-140.

29. Peile E. Evidence-based medicine and values-based medicine: partners in clinical education as well as in clinical practice. BMC Med. 2013; 11:40.

30. Weeks JC, Catalano PJ, Cronin A, et al. Patients' expectations about effects of chemotherapy for advanced cancer. $N$ Engl J Med. 2012;367(17): 1616-1625.

31. Porter ME, Teisberg EO. Redefining Health Care: Creating Value-Based Competition on Results. Harvard Business Press (US); 2006.

32. Porter ME, Lee TH. The strategy that will fix health care. Harv Bus Rev. 2013;91(12):24.

33. Porter ME, Teisberg EO. How physicians can change the future of health care. JAMA. 2007;297(10):1103-1111.

34. Porter ME. What is value in health care? N Engl J Med. 2010;363(26): 2477-2481.

35. Porter ME. A strategy for health care reform - toward a value-based system. N Engl J Med. 2009;361(2):109-112.

36. Dunbar-Rees R, Panch T, Dancy M. From volume to value? Can a value-based approach help deliver the ambitious aims of the NHS cardiovascular disease outcomes strategy?. Heart. 2014;100(11): $827-832$.

37. Mangiafico L, Perja M, Fusco F, Riva S, Mago D, Gringeri A. Safety and effectiveness of raltegravir in patients with haemophilia and anti-HIV multidrug resistance. Haemophilia. 2012;18(1):108-111.

38. Riva S, Cutica I, Krampe C, et al. A cohort pilot study on HIV-associated neuropsychological impairments in hemophilia patients. Front Human Neurosci. 2015;9:313.

39. Porter ME, Lee TH. Why health care is stuck — and how to fix it. Harvard Business Review Blog Network. [webpage on the Internet]; 2013 Available from https://hbr.org/2013/09/why-health-care-is-stuck-andhow-to-fix-it. Accessed February 17, 2017. 
40. Hedberg C, Lynøe N. What is meant by patient-centredness being value-based? Scand J Prim Health Care. 2013;31(4):188-189.

41. Institute of Medicine. Crossing the Quality Chasm: A New Health System for the 21st Century. Washington, DC: National Academies Press; 2001.

42. Ganz PA. Delivering on the promise of patient-centered care. J Natl Compr Canc Netw. 2015;13(4):495-497.

43. Pravettoni G, Gorini A. A P5 cancer medicine approach: why personalized medicine cannot ignore psychology. J Eval Clin Pract. 2011; 17(4):594-596.

44. Gibbons RJ, Abrams J, Chatterjee K, et al. ACC/AHA 2002 guideline update for the management of patients with chronic stable angina--summary article: a report of the American College of Cardiology/American Heart Association Task Force on Practice Guidelines (Committee on the Management of Patients With Chronic Stable Angina). Circulation. 2003;107(1):149-158.
45. Shaw LJ, Mieres JH, Hendel RH, et al. Comparative effectiveness of exercise electrocardiography with or without myocardial perfusion single photon emission computed tomography in women with suspected coronary artery disease results from the What is the Optimal Method for ischemia Evaluation in WomeN (WOMEN) trial. Circulation. 2011;124(11):1239-1249.

46. Negrouk A, Horgan D, Gorini A, et al. Clinical trials, data protection and patient empowerment in the era of the new EU regulations. Public Health Genomics. 2015;18(6):386-395.

47. Fumagalli LP, Radaelli G, Lettieri E, Masella C. Patient empowerment and its neighbours: clarifying the boundaries and their mutual relationships. Health Policy. 2015;119(3):384-394.

48. Monteagudo, JL, Moreno O. ICT Enhanced Patient Empowerment. Report on Priority Topic Cluster Two and recommendations, in WP 2deliverable D 2.4. eHealth ERA Project: Towards the Establishment of a European Research AREA; 2007. Research Area of Telemedicine and Information Society, Institute of Health Carlos III: Madrid, Spain.
Journal of Multidisciplinary Healthcare

\section{Publish your work in this journal}

The Journal of Multidisciplinary Healthcare is an international, peerreviewed open-access journal that aims to represent and publish research in healthcare areas delivered by practitioners of different disciplines. This includes studies and reviews conducted by multidisciplinary teams as well as research which evaluates the results or conduct of such teams or health care processes in general. The journal covers a very wide range of areas and welcomes submissions from practitioners at all levels, from all over the world. The manuscript management system is completely online and includes a very quick and fair peer-review system. Visit http://www.dovepress.com/ testimonials.php to read real quotes from published authors. 